\title{
Understanding the Price of Volatility Risk in Carry Trades
}

\author{
March 11, 2015
}

\begin{abstract}
This paper investigates the cross-sectional pricing ability of the short- and long-run components of global foreign exchange (FX) volatility for carry trade returns. We find a negative and statistically significant factor risk price for the long-run component, but no significant pricing effect due to the short-run volatility component. We also document that the dynamics of the longrun component of global FX volatility are related to US macroeconomic fundamentals. Our results are robust to various parametrizations of the volatility models used to obtain the volatility components and they are invariant to alternative asset pricing testing methodologies and sample periods.
\end{abstract}

JEL Classification: F31, G12, and G15.

Keywords: Carry Trade, Forward Premium Puzzle, and Volatility Risk. 


\section{Introduction}

The uncovered interest rate parity (UIP) condition postulates that the expected foreign exchange (FX) gain between two currencies must be offset by their interest rate differential. Assuming that there are no arbitrage opportunities and therefore the interest rate differential equals the forward premium, UIP then implies that the expected exchange rate change must equal the current forward premium. This condition is routinely assumed in models of international macroeconomics and finance. The empirical failure of UIP has been documented in a vast literature over the past 40 years (see, among others, Hansen and Hodrick (1980), Fama (1984), Engel (1996), Sarno, Valente, and Leon (2006), Burnside (2012), and the references therein), and a popular speculative strategy based on the violation of the parity (i.e., FX carry trade) has gained much attention in recent academic studies. The strategy involves borrowing in low interest rate currencies and investing in high interest rate currencies and over the years it has yielded sizable returns. One of the potential rationalizations of this evidence is based on a risk argument: currencies with high interest rates are riskier than low interest rate currencies and therefore deliver higher expected returns as a compensation for bearing time-varying risk (Fama (1984)). Albeit appealing, conventional measures of risk, such as stock market excess returns, consumption growth, term premium, and Fama and French (1993) factors have not consistently explained carry trade returns (see Burnside, Eichenbaum, Kleshchelski, and Rebelo (2011) and the references therein). In a recent study, Menkhoff, Sarno, Schmeling, and Schrimpf (2012), adopting a cross-sectional asset pricing framework, show that high returns from currency speculation can be understood as compensation for bearing global FX volatility risk. ${ }^{1}$ On the basis of the predictions of the intertemporal capital asset pricing model (ICAPM), the authors argue that negative volatility risk premia arise because positive volatility shocks worsen the investors' risk-return tradeoff. Their approach is successful in adequately pricing the cross-section of carry trade returns, as their global FX volatility factor dominates other relevant risk measures, including FX market liquidity.

A somehow unrelated literature, concerned with modeling the volatility of asset returns, has shown that empirical models containing only one component are often inadequate to capture the salient features of asset returns. In fact, empirical observation has shown that the

\footnotetext{
${ }^{1}$ Lustig and Verdelhan (2007) and Lustig, Roussanov, and Verdelhan (2011) are among the first to propose a cross-sectional asset pricing framework in the context of FX markets. These studies also record some success in explaining the cross-section of carry trade returns by employing currency-based risk factors. See also Burnside, Eichenbaum, Kleshchelski, and Rebelo (2011), Burnside, Eichenbaum, and Rebelo (2011), and Mancini, Ranaldo, and Wrampelmeyer (2013).
} 
volatility of low-frequency returns tends to be more persistent than the volatility of highfrequency returns (Engle and Lee (1999) and the references therein). As a consequence, models comprising one highly persistent and one quickly mean-reverting volatility components have been found to systematically outperform one-component specifications (see, among others, Chernov, Gallant, Ghysels, and Tauchen (2003), Bollerslev and Zhou (2006), Christoffersen, Jacobs, Ornthanalai, and Wang (2008), and the references therein). The two volatility components have been rationalized on various grounds: Andersen and Bollerslev (1997) and Müller, Dacorogna, Davé, Olsen, Pictet, and Weizsäcker (1997) argue that different degrees of persistence of volatility are driven by the heterogeneity of news arrival process or investors' investment horizons. Others suggest that investors' sensitivity to new information is timevarying, which leads to a separate source of randomness (Liesenfeld (2001)) and short-run volatility effects can be dominating over certain periods of time because of extreme market movements, heterogeneous market participants, and transitory market regulations (MacKinlay and Park (2004)). The common theme of the findings recorded in these studies is that empirical investigations of the asset returns volatility should be carried out using models with multiple factors. In line with this prescription, Adrian and Rosenberg (2008) investigate the crosssectional pricing ability of volatility risk by decomposing the US equity market volatility into short- and long-run components. The authors find that both components are significant priced factors and their proposed model compares favourably against existing benchmark models.

In this paper, we combine these two separate literatures and, building upon Adrian and Rosenberg (2008) and Menkhoff, Sarno, Schmeling, and Schrimpf (2012), we explore the asset pricing power of the short- and long-run components of global FX volatility in the cross-section of carry trade returns. The rationale for this investigation is that investors in FX markets may not react in the same way to volatility shocks that are expected to be transitory compared to highly persistent ones. Hence, innovations in the short-run component of global FX volatility may carry a price of risk significantly different from the one exhibited by the long-run component. Put differently, each of the two volatility components may have its own asset pricing effect depending on whether it reflects improvements or deteriorations in different aspects of the investment opportunity set.

Another important goal of this paper is to explain FX volatility risk in light of variations in macroeconomic conditions. Since the influential paper by Meese and Rogoff (1983), researchers have focused their attention towards explaining the missing link between exchange rate variations and macroeconomic fundamentals. This link has not been fully recovered although recent attempts have recorded some success (see Della Corte, Riddiough, and Sarno 
(2014) and the references therein). The study by Menkhoff, Sarno, Schmeling, and Schrimpf (2012) is certainly successful in explaining the cross-section of carry trade returns. However, it is silent about any potential links between volatility risk and macroeconomic fundamentals. Furthermore, Burnside, Eichenbaum, Kleshchelski, and Rebelo (2011) and Burnside (2012) show that, in the context of FX markets, proxies for business cycle risk have no significant covariation with carry trade payoffs. Given the large body of evidence relating FX movements to macroeconomic news (see, among others, Andersen and Bollerslev (1998), Andersen, Bollerslev, Diebold, and Vega (2003), Engel, Mark, and West (2008), and Evans and Lyons (2008)), it is natural to hypothesize an existing link between global FX volatility and macroeconomic fundamentals. Hence, investigating whether fluctuations in macroeconomic fundamentals influence the components of global FX volatility can provide new insights into this elusive issue. ${ }^{2}$

Our empirical analysis uncovers a host of interesting results. First, using a crosssectional asset pricing framework, we find that only the long-run component of global FX volatility is a significant priced factor in the cross-section of carry trade returns. In fact, the short-run component of global FX volatility is not statistically significant in any of the asset pricing tests carried out in this paper. This result is robust against different parametrization of the volatility models and different methodologies used to compute volatility components. Second, we are able to uncover a significant relationship between FX volatility risk and macroeconomic fundamentals as long-run global FX volatility dynamics are significantly related to US macroeconomic fundamental shocks, especially industrial production and money balances. All results are robust against different methodologies used to carry out asset pricing tests and across different subperiods of the sample.

The remainder of the paper is organized as follows. The next section discusses the empirical framework used to estimate the components of global FX volatility and carry out asset pricing tests. Section 3 describes the data and discusses the descriptive statistics of the carry trade portfolios over the sample period. Section 4 reports the main empirical results, while Section 5 discusses a battery of the robustness checks of the main empirical findings. Section 6 explores the relationship between volatility components and macroeconomic fundamentals and a final section concludes.

\footnotetext{
${ }^{2}$ It is worthwhile noting that Adrian and Rosenberg (2008) found that the long-run component of US equity market volatility relates to business cycle risk. However, to the best of our knowledge similar evidence has not been recorded in the context of FX markets.
} 


\section{Empirical Framework}

\subsection{Global FX Returns}

We first construct a measure to proxy for global FX return on any trading day $\tau$ as the average of discrete returns for all currencies available on that trading day in the main sample spot FX market. The proxy is thus given by

$$
R_{\tau}=\sum_{k \in K_{\tau}}\left[\left(\frac{S_{\tau}^{k}-S_{\tau-1}^{k}}{S_{\tau-1}^{k}}\right) / K_{\tau}\right] \text {, }
$$

where $S_{\tau}^{k}$ and $K_{\tau}$ denote the spot exchange rate of currency $k$ and the number of available currencies on day $\tau$, respectively. We appeal to this equally weighted measure of global FX return on data availability grounds. More specifically, daily data on currency order flows as well as the shares of respective currencies in international trade or reserves are publicly unavailable for a large section of our sample. This prohibits estimating the weights of the constituent currencies in a reasonable way. We consider discrete return for each currency instead of log return, which is consistent with the computation of currency excess returns described in Section 3.2. ${ }^{3}$

\subsection{Volatility Component Models}

We model the volatility of global FX returns and identify the short- and long-run components by using two empirical models that have been proven successful at capturing the salient features of the volatility of daily asset returns. ${ }^{4}$ The first candidate we consider is the component GARCH (CGARCH) model introduced by Engle and Lee (1999) to parametrically capture global FX volatility dynamics at different horizons. The model decomposes the conditional volatility process into two separate AR components: (1) a time-varying long-run trend component; and (2) a short-run transitory component as deviations from the trend. The conditional mean and the short- and long-run components are specified as

$$
\begin{aligned}
& R_{\tau}=\psi_{1}+\epsilon_{\tau}, \quad \epsilon_{\tau}=\sigma_{\tau} v_{\tau}, \quad v_{\tau} \sim \text { i.i.d. } N(0,1) \\
& \sigma_{\tau}^{2}-q_{\tau}=\psi_{2}\left(\epsilon_{\tau-1}^{2}-q_{\tau-1}\right)+\psi_{3}\left(\epsilon_{\tau-1}^{2}-q_{\tau-1}\right) d_{\tau-1}+\psi_{4}\left(\sigma_{\tau-1}^{2}-q_{\tau-1}\right) \\
& q_{\tau}=\psi_{5}+\psi_{6}\left(q_{\tau-1}-\psi_{5}\right)+\psi_{7}\left(\epsilon_{\tau-1}^{2}-\sigma_{\tau-1}^{2}\right) .
\end{aligned}
$$

\footnotetext{
${ }^{3}$ Using log returns instead of discrete returns has an immaterial effect on the subsequent empirical results.

${ }^{4} \mathrm{We}$ consider alternative modeling strategies that do not rely on parametric generalized autoregressive conditional heteroskedastic $(\mathrm{GARCH})$ models in the robustness Section 5.1.
} 
In equation (2), $v_{\tau}$ denotes an independently and identically distributed normal error term. We use $\sigma_{\tau}^{2}-q_{\tau}$ and $q_{\tau}$ to represent the short- and long-run components of the conditional variance $\sigma_{\tau}^{2}$, respectively. The sum of the parameters $\psi_{2}$ and $\psi_{4}$ measures the noisier transitory shock persistence. The parameter $\psi_{7}$ represents the initial effect of a shock to the long-run component, while the $\mathrm{AR}$ root $\psi_{6}$ measures the shock persistence of the longrun component. The volatility dynamics for the short-run component require convergence to zero at a geometric rate of $\psi_{2}+\psi_{4}<\psi_{6}$. In contrast, the long-run component requires slower convergence to its unconditional mean $\psi_{5}$ at a geometric rate of $\psi_{6}$. The individual means of the short- and long-run components are not separately identifiable in the model. The two components determine the conditional volatility process additively. The model estimates only the unconditional mean $\psi_{5}$ of the long-run component. Finally, the volatility decomposition model allows for asymmetric effects upon "new information" arrival on the short-run component by incorporating a dummy variable $d_{\tau-1}$ in equation (3), that is, $d_{\tau-1}$ takes the value 1 if $\epsilon_{\tau-1}<0$ and zero otherwise. ${ }^{5}$

The second candidate we consider, in line with Adrian and Rosenberg (2008), is a component exponential GARCH-in-mean (henceforth CEGARCH) model. The model allows for a richer parametrization of the conditional variance of returns since an asymmetric relationship between global FX returns and both the short- and long-run volatility components is explicitly considered. More precisely, the conditional mean and the volatility components are given by

$$
\begin{aligned}
& R_{\tau}=\theta_{1}+\theta_{2} s_{\tau-1+} \theta_{3} l_{\tau-1+} \sqrt{v_{\tau-1}} \varepsilon_{\tau}, \log \sqrt{v_{\tau}}=s_{\tau}+l_{\tau}, \quad \varepsilon_{\tau} \sim \text { i.i.d. } N(0,1) \\
& s_{\tau}=\theta_{4} s_{\tau-1}+\theta_{5} \varepsilon_{\tau}+\theta_{6}\left(\left|\varepsilon_{\tau}\right|-\sqrt{2 / \pi}\right) \\
& l_{\tau}=\theta_{7}+\theta_{8} l_{\tau-1}+\theta_{9} \varepsilon_{\tau}+\theta_{10}\left(\left|\varepsilon_{\tau}\right|-\sqrt{2 / \pi}\right)
\end{aligned}
$$

where $\varepsilon_{\tau}$ is an independently and identically distributed normal error term with zero mean and unit variance, $s_{\tau}$ is the (quickly mean-reverting) short-run component (with $\theta_{4}<\theta_{8}$ ), and $l_{\tau}$ is the (slowly mean-reverting) long-run component. The terms $\left|\varepsilon_{\tau}\right|-\sqrt{2 / \pi}$ in equations (6) and (7) denote the shocks to the volatility components and their expected values are equal to zero under the normality of $\varepsilon_{\tau}$. Similar to Adrian and Rosenberg (2008), we also normalize the

\footnotetext{
${ }^{5}$ The implementation of the CGARCH model requires parameters to satisfy restrictions of $0<\psi_{2}+\psi_{4}<$ $\psi_{6}<1,0<\psi_{7}<\psi_{4}<\psi_{6}<1$, and $\psi_{5}, \psi_{2}>0$ in order to: (1) identify individual volatility components separately; (2) ensure a positive conditional variance; and (3) attain sufficiency condition for covariance stationarity. There is no sign restriction on the coefficient $\left(\psi_{3}\right)$ for the asymmetric effect term. But its statistical significance implies the presence of a threshold effect.
} 
unconditional mean of $s_{\tau}$ to be zero. The coefficients $\theta_{5}$ and $\theta_{9}$ measure the asymmetric effects of returns on the short- and long-run components of volatility.

\subsection{Asset Pricing Tests}

After decomposing the volatility of global FX returns into short- and long-run components, we assess their pricing power in the cross-section of carry trade returns. Riskbased explanations for carry trade returns suggest that in the absence of arbitrage opportunities, excess return on each portfolio $i$ has a zero price. This implies that excess return to a portfolio must satisfy:

$$
E_{t}\left[m_{t+1} z_{t+1}^{i}\right]=0
$$

where $E_{t}$ is the expectations operator conditional on information available at the end of period $t, z_{t+1}^{i}$ is the excess return on a carry trade portfolio $i$, and $m_{t+1}$ is the stochastic discount factor (SDF). Restricting the SDF to be linear in the vector of pricing factors gives

$$
m_{t}=1-\left(h_{t}-\mu\right)^{\prime} b
$$

where $h_{t}$ is a $j \times 1$ vector of risk factors, $\mu=E\left(h_{t}\right)$, and $b$ is a $j \times 1$ vector of SDF parameters. Given equations (8) and (9), there exists a $j \times 1$ vector of factor risk prices $\lambda=$ $\sum_{h} b$ such that

$$
E\left[z_{t}^{i}\right]=\beta_{i}^{\prime} \lambda
$$

where $\sum_{h}=E\left[\left(h_{t}-\mu\right)\left(h_{t}-\mu\right)^{\prime}\right]$ is the factor covariance matrix and $\beta_{i}$ are the population coefficients in a regression of $z_{t}^{i}$ on risk factors $h_{t}$. The beta representation in equation (10) states that expected excess returns for portfolio $i$ depends on aggregate risk exposure quantities (also called factor sensitivities or loadings) $\beta_{i}$ and factor risk prices $\lambda$. Focusing on the innovations of the short- and long-run components of global FX volatility (denoted by SRVI and LRVI, respectively) in addition to other risk factors found to be successful in pricing the cross-section of carry trade returns (denoted by $X$ ), the beta representation of the corresponding linear factor pricing model can therefore be written as

$$
E\left[z_{t}^{i}\right]=\lambda_{X} \beta_{i, X}+\lambda_{S R V I} \beta_{i, S R V I}+\lambda_{L R V I} \beta_{i, L R V I}
$$

Fama and MacBeth (1973) show a two-pass ordinary least squares regression procedure which we follow to estimate the parameters of equation (11). The first-pass involves timeseries regressions of monthly excess returns for portfolio $i$ on a constant $\alpha_{i}$, factor $X$, and innovations of the short- and long-run components. The regression specification is given by 


$$
z_{t}^{i}=\alpha_{i}+\beta_{i, X} X_{t}+\beta_{i, S R V I} S R V I_{t}+\beta_{i, L R V I} L R V I_{t}+e_{t}^{i}
$$

where $t=1,2, \ldots \ldots, T$. The obtained betas are then utilized in the second-pass cross-sectional regression of average excess returns to get estimated factor risk prices $\hat{\lambda}$. The cross-sectional regression is expressed as

$$
\bar{z}^{i}=\lambda_{X} \hat{\beta}_{i, X}+\lambda_{S R V I} \hat{\beta}_{i, S R V I}+\lambda_{L R V I} \hat{\beta}_{i, L R V I}+\zeta_{i}
$$

where $\bar{z}^{i}=\frac{1}{T} \sum_{t=1}^{T} z_{t}^{i}$ and the regression residuals $\zeta_{i}$ represent the pricing errors. The secondpass regression is performed without a constant $\left(\lambda_{0}=0\right)$ since we do not allow mispricing common to the cross-section of excess returns for portfolios. ${ }^{6}$

The two-pass regressions, however, suffer from an errors-in-variable problem. The betas used in the second-pass are estimates of the true unknown betas. To overcome this econometric issue, we correct standard errors following Shanken (1992). Jagannathan and Wang (1998) point out that the Shanken (1992) correction is inappropriate as well under heteroskedastic returns. For this reason, we also carry out a generalized method of moments (GMM) procedure advocated by Cochrane (2005). ${ }^{7}$

\section{Data and Currency Portfolios}

\subsection{Data}

The data used in this paper consist of bid, ask, and midpoint quotes for daily spot and one-month forward exchange rates against the US dollar (USD) sourced from Barclays Bank International and World Markets PLC/Reuters (WMR) via Datastream. We construct the proxy for global FX return using the midpoint spot quotes at a daily frequency covering the sample period from November 2, 1983 to February 28, 2013. The main sample contains currencies from 48 countries: Australia, Austria, Belgium, Brazil, Bulgaria, Canada, Croatia, Cyprus, the Czech Republic, Denmark, Egypt, Euro area, Finland, France, Germany, Greece, Hong Kong, Hungary, Iceland, India, Indonesia, Ireland, Israel, Italy, Japan, Kuwait, Malaysia, Mexico, the

\footnotetext{
${ }^{6}$ In the empirical investigation, we use the US dollar risk factor (DOL) suggested by Lustig, Roussanov, and Verdelhan (2011) as a proxy for the risk factor $X$. The second-pass regression is carried out without an intercept. This is due to the fact that the estimated betas for the DOL factor reported in Section 4.2 have little pricing power in the cross-section of carry trade returns. The factor itself serves the function of a constant that allows pricing errors shared by currency portfolios. See on this issue, Lustig, Roussanov, and Verdelhan (2011), Burnside (2012), and Menkhoff, Sarno, Schmeling, and Schrimpf (2012).

${ }^{7}$ We test the null hypothesis that all (estimated) pricing errors are jointly equal to zero with the statistic: $J=$ $T \widehat{\zeta}^{\prime} \widehat{\Omega}_{\hat{\zeta}}^{-1} \widehat{\zeta}$, where $\widehat{\Omega}_{\hat{\zeta}}$ is a consistent estimator for the asymptotic covariance matrix of $\sqrt{T} \hat{\zeta}$. The test statistic asymptotically follows the $\chi_{P-j}^{2}$ distribution.
} 
Netherlands, New Zealand, Norway, Philippines, Poland, Portugal, Russia, Saudi Arabia, Singapore, Slovakia, Slovenia, South Africa, South Korea, Spain, Sweden, Switzerland, Taiwan, Thailand, Ukraine, and the United Kingdom. ${ }^{8}$ The number of currencies increases as data on more currencies, especially from developing countries, become available. The total number of currencies varies over the sample period with a minimum of 9 and a maximum of 37.

\subsection{Carry Trade Portfolios}

At the end of each month $t$, currencies are assigned to five portfolios based on their forward discounts $\left(F_{t}^{k}-S_{t}^{k}\right) / S_{t}^{k}$ observed at the end of month $t$. We use $S_{t}^{k}$ and $F_{t}^{k}$ to denote the levels of daily spot and one-month forward exchange rates of currency $k$ against the USD, respectively, at the end of month $t$. We rebalance currency portfolios at the end of every month. Currencies are ranked in ascending order with respect to their forward discounts or, equivalently, to their interest rate differentials. This results in portfolio 1 comprising $20 \%$ of currencies with the smallest forward discounts (or lowest interest rates), while portfolio 5 comprising $20 \%$ of currencies with the largest forward discounts (or highest interest rates). The monthly excess return to an investor buying a foreign currency $k$ in the forward exchange market and selling back the currency in the spot market next month is estimated as $z_{t+1}^{k}=$ $\left(F_{t}^{k}-S_{t+1}^{k}\right) / S_{t}^{k}$. We compute the excess return $z_{t+1}^{i}$ for currency portfolio $i=1,2, \ldots, 5$ constructed at the end of month $t$, but realized at the end of month $t+1$ as the equally weighted average of excess returns for the constituent currencies.

Previous empirical studies (e.g., Burnside, Eichenbaum, and Rebelo (2007), Burnside, Eichenbaum, Kleshchelski, and Rebelo (2011), and Lustig, Roussanov, and Verdelhan (2011, 2014)) on carry trades suggest that transaction costs are quantitatively important, especially for developing countries. Acknowledging this possibility, we also compute net excess returns for all foreign currencies using the bid-ask quotes as in Menkhoff, Sarno, Schmeling, and Schrimpf (2012). ${ }^{9}$ Following Lustig, Roussanov, and Verdelhan (2011) we also construct two additional

\footnotetext{
${ }^{8}$ We also consider a smaller subsample consisting only of 15 developed countries to further comprehend the empirical results obtained for the main sample. The list includes: Australia, Belgium, Canada, Denmark, Euro area, France, Germany, Italy, Japan, the Netherlands, New Zealand, Norway, Sweden, Switzerland, and the United Kingdom. The currency coverage is as in Lustig, Roussanov, and Verdelhan (2011) and Menkhoff, Sarno, Schmeling, and Schrimpf (2012).

${ }^{9}$ The net excess returns estimated using the bid-ask quotes from WMR should be regarded as conservative estimates relative to returns if estimated using the effective inter-dealer quotes in FX markets. The quoted bid-ask spreads, although indicative of the daily market condition, are roughly twice larger than the effective inter-dealer spreads (Lyons (2001)).
} 
portfolios both for transaction cost unadjusted and adjusted returns. They are: (1) the average portfolio denoted by DOL (i.e., the US dollar risk factor), which is the equally weighted average of the five currency portfolios; and (2) the long-short carry trade portfolio denoted by HML, which is the combination of a long position in portfolio 5 and a short position in portfolio 1.

The summary statistics of the five currency portfolios, the DOL and HML portfolios based on the sample of 48 countries are presented in Table 1. Panel A reports results for cost unadjusted excess returns, while panel B provides results for excess returns net of transaction costs. Both unadjusted and adjusted annualized average excess returns increase monotonically when moving from portfolio 1 to portfolio 5 and the HML portfolio. But the payoffs to the carry trade portfolios shrink with the bid-ask spreads relative to those of the unadjusted returns. We also carry out a formal test for the null of no-increasing monotonicity of portfolio returns as in Patton and Timmermann (2010) and find that the null hypothesis is rejected with p-values virtually equal to zero.

The annualized average excess return for the DOL portfolio is $1.91 \%$ and this becomes $1.07 \%$ when bid-ask spreads are taken into account. These numbers imply that currency speculators with access to forward markets demand a low but positive risk premium for taking long position in foreign currency. There is a sizable spread of $7.99 \%$ (5.09\% net of transaction costs) between the annualized excess returns on portfolio 5 and portfolio 1 (i.e., excess return for the HML portfolio). The skewness of portfolio excess returns recorded in Table 1 is generally consistent with Brunnermeier, Nagel, and Pedersen (2009), who show that currencies with high interest rate differentials are related to negative conditional skewness of exchange rate movements. The annualized Sharpe ratios increase monotonically as we move from currency portfolio 1 to portfolio 5 and the HML carry trade portfolio and, even after controlling for bid-ask spreads, the Sharpe ratios for portfolio 5 and the HML portfolio are notable. ${ }^{10}$

\section{Empirical Results}

\subsection{Estimation of the Volatility Components}

In line with the existing literature (see, among others, Merton (1980), Nelson (1992), and Andersen, Bollerslev, Diebold, and Labys (2003), and the references therein), we estimate

\footnotetext{
${ }^{10}$ We also compute descriptive statistics for the five carry trade portfolios, the DOL and HML carry trade portfolios constructed using the subsample of 15 developed countries. The results reported in Table A1 of the Internet Appendix confirms qualitatively and quantitatively the ones reported in Table 1.
} 
the volatility component models introduced in Section 2.2 using daily data on global FX return. We also apply an $\operatorname{ARMA}(3,1)$ filter in the conditional mean of the CGARCH model to remove lower order autocorrelation dependencies in the disturbances.

The results on the estimation of the CGARCH model are reported in Table 2. The shortand long-run components of global FX conditional volatility are identified by their relative magnitudes of autocorrelation coefficients. In particular, the estimated AR coefficient $\left(\widehat{\psi_{4}}\right)$ for the short-run component is 0.879 , which is relatively smaller than the AR coefficient $\left(\widehat{\psi_{6}}\right)$ of 0.994 for the long-run component. ${ }^{11}$ Both these coefficient estimates are significantly different from zero at the $1 \%$ conventional level. Although the long-run component exhibits a highly persistent shock process, it is not permanent. We reject the null hypothesis that $\psi_{6}=1$ at the $5 \%$ significance level. The AR coefficient $\widehat{\psi_{6}}$ exceeds the sum of coefficients $\widehat{\psi_{2}}$ and $\widehat{\psi_{4}}$ in magnitude implying relatively slower mean-reversion process in the long-run. The estimated coefficient $\left(\widehat{\psi_{3}}\right)$ for the asymmetric effects is negative and significant, which suggests that short-run volatility increases more in reaction to unexpected USD appreciation. All other coefficients are statistically significant at the $1 \%$ or $5 \%$ level and have the expected signs. ${ }^{12}$ The Ljung and Box (1978) $Q$-statistics at 10, 20, and 30 lags, respectively, confirm that both the standardized and squared standardized residuals are serially uncorrelated.

We report the results on the estimation of the CEGARCH model in Table 3. The model identifies a long-run volatility component whose first-order serial correlation is virtually indistinguishable from the one exhibited by the CGARCH model in Table 2 (0.992 vs. 0.994). However, the serial correlation of the short-run volatility component is substantially lower. Consistent with Adrian and Rosenberg (2008), the estimated parameters $\widehat{\theta_{2}}$ and $\widehat{\theta_{3}}$ are statistically significant and exhibit the same sign pattern recorded for the US equity market volatility. However, differently from the US equity market, the asymmetric effect is positive and statistically significant only for the short-run component of volatility (i.e., USD appreciation increases short-run volatility), in line with the implication of the estimate reported in Table 2. Such effect is not present in the long-run volatility component, as the parameter $\widehat{\theta_{9}}$

${ }^{11}$ These values are in line with those reported for FX volatility decomposition in the literature (e.g., Maheu (2005)).

12 The conditional variance estimate can be related to the global FX volatility measure of Menkhoff, Sarno, Schmeling, and Schrimpf (2012). To show this, we first take the square-root of the time-series on estimated conditional variance and average the resultant series over the number of trading days in each month. We then construct the Menkhoff, Sarno, Schmeling, and Schrimpf (2012) measure of global FX volatility in each month $t$ as $\sigma_{t}^{F X}=\frac{1}{T_{t}} \sum_{\tau \in T_{t}}\left[\sum_{k \in K_{\tau}}\left(\left|\frac{S_{\tau}^{k}-S_{\tau-1}^{k}}{S_{\tau-1}^{k}}\right| / K_{\tau}\right)\right]$, where $T_{t}$ denotes the total number of trading days in month $t$. The correlation between these two versions of global $\mathrm{FX}$ volatilities is $+79 \%$. 
is insignificantly positive. These results are generally in line with the findings reported in existing studies which consider asymmetric effects only in the short-run component of FX volatility (see Byrne and Davis (2005) and the references therein). Furthermore, the Ljung and Box (1978) $Q$-statistics suggest a potential misspecification of the volatility decomposition model in the form suggested by Adrian and Rosenberg (2008) when applied to the FX market.

At face value, the results reported in Tables 2 and 3 suggest that a CGARCH model may represent a better parametrization, in comparison with a CEGARCH model, to capture the salient features of global FX volatility. We formally evaluate this finding by carrying out a battery of additional tests. Conventional likelihood ratio tests are not easily applicable in our context because the two volatility models are not nested. ${ }^{13}$ As an alternative, several studies have used out-of-sample tests for model validation (see, among others, Inoue and Kilian (2004, 2006), Caporin and McAleer (2010), and the references therein). In fact, out-of-sample forecasting tests allowed researchers to circumvent the inference problems associated with testing non-nested models. Along this line of reasoning, we carry out the testing procedure recently proposed by Patton (2011) for testing the null hypothesis of equal predictions originating from volatility models even in the presence of imperfect volatility proxies. ${ }^{14}$

The results of this exercise are reported in Table 4. The test statistics are computed for different functional form of the loss function, as suggested in Patton (2011, pp. 252-253), and for global FX volatility forecasts computed both at daily and monthly frequencies. In all cases, the null of equality of volatility predictions originating from the CGARCH and CEGARCH models cannot be rejected at any conventional level. This suggests that the more parsimonious $\mathrm{CGARCH}$ model is able to generate forecasts which are not statistically different from the ones generated from the richer CEGARCH model. Moreover, the out-of-sample predictions (both at daily and monthly frequencies) of the short- and long-run volatilities generated by the CGARCH model are highly correlated with those generated by the CEGARCH model. The correlation exceeds $+80 \%$ in all cases.

In light of these results, and consistent with a parsimony argument, we will use a CGARCH model in the subsequent sections of this paper to explore the asset pricing effects of FX volatility risk in the cross-section of carry trade returns. ${ }^{15}$

\footnotetext{
${ }^{13}$ Although some alternative testing procedures have been proposed in the literature to compare the in-sample performance of non-nested volatility models (Lee and Brorsen (1997), Kobayashi and Shi (2005), and the references therein), they are either unsuitable to our case.

${ }^{14}$ Full details of the out-of-sample volatility testing procedure are reported in the Internet Appendix.

${ }^{15} \mathrm{We}$ have also carried out a thorough robustness check on the results of our asset pricing tests using alternative frameworks used to decompose global FX volatility, which are not based on GARCH models. The
} 


\subsection{Asset Pricing Results}

We carry out asset pricing tests by using the innovations in the short- and long-run components from the CGARCH model. As the analysis is carried out at the monthly level, for consistency with previous studies, we compute monthly short- and long-run components as the end-of-month values of the corresponding daily series. ${ }^{16}$ Figure 1 shows the time-series plots of the global FX volatility components at the monthly frequency. Innovations of the short- and long-run components are computed as first differences of the estimated monthly volatility components. ${ }^{17}$

The results of the asset pricing tests for transaction cost unadjusted currency portfolios are reported in Table 5. Panel A reports estimated factor betas from the first-pass time-series regressions for five portfolios built using all and developed country samples. Portfolio 1 has a positive loading on innovations of the short-run component of global FX volatility, while portfolio 5 a negative loading for all countries. The corresponding loadings are both negative for the sample of developed countries. The beta estimates for portfolios 2 to 4 are all positive except that for portfolio 3 in both samples. The estimated factor loadings $\hat{\beta}_{i, S R V I}$ for all but portfolio 3 turn out to be statistically insignificant based on the GMM-HAC standard errors. Focusing on the innovations of the long-run component, we find that the loadings are positive for portfolio 1 and negative for portfolio 5. That is, excess returns for the portfolio with currencies in the lowest forward discount (or, equivalently, interest rate) quintile covary positively with innovations in the long-run component of global FX volatility. Conversely, excess returns of the portfolio with currencies in the highest forward discount quintile covary negatively. The GMM-HAC standard errors suggest that the estimated factor loadings $\hat{\beta}_{1, L R V I}$ and $\hat{\beta}_{5, L R V I}$ are significantly different from zero. Besides, a monotonically decreasing pattern emerges for the loadings $\hat{\beta}_{i, L R V I}$ as we move from portfolio 1 to portfolio 5 based on the sample of all countries. The beta estimates exhibit a decreasing pattern for developed countries. The portfolios load positively on the DOL factor as expected and the betas hover

results, discussed in Section 5.1, confirm our baseline findings and they are reported in Tables IA4-IA6 of the Internet Appendix.

16 The end-of-month estimates of volatility components closely follow their average-of-month counterparts. The correlations between the end- and average-of-month series are $+93 \%$ and $+92 \%$ for the short- and long-run components, respectively. The corresponding correlations increase to $+96 \%$ and $+94 \%$ for the sample period considered in asset pricing regressions.

${ }^{17}$ Descriptive statistics for both of the innovation series at a monthly frequency are reported in Table A2 of the Internet Appendix. We drop first 42 months of data on volatility component innovations (as burn-in period) and perform asset pricing analysis covering the period from May 1987 to February 2013. 
closely around one. The estimated risk quantities $\hat{\beta}_{i, D O L}$ are highly significant regardless of sample currency compositions.

Panel B in Table 5 shows estimates of the factor risk prices obtained from the secondpass cross-sectional regressions. The risk price estimate for the short-run volatility component, $\hat{\lambda}_{S R V I}$, is negative but economically negligible. The GMM-HAC and Shanken (1992) corrected standard errors also imply that the estimated risk price is statistically insignificant irrespective of samples. This is not too surprising since most of the corresponding estimated betas in the first-pass regressions are insignificantly different from zero. We find that the risk price estimate for the long-run volatility component, $\hat{\lambda}_{L R V I}$, is -0.097 for the all country sample and -0.048 for the developed country sample. The estimated factor risk prices are also significantly different from zero. The negative factor risk price estimate implies that currency portfolios whose excess returns covary positively with long-run component innovations earn lower risk premia as they provide a hedge against increased volatility risk attributed to the long-run component. In contrast, portfolios whose excess returns covary negatively with long-run component innovations demand a higher risk premium. Consistent with other studies in this strand of literature (e.g., Burnside (2012) and Lustig, Roussanov, and Verdelhan (2011)), the estimated risk price on the DOL factor is positive but insignificantly different from zero. This implies that the factor explains none of the cross-sectional variation in payoffs to the currency speculation strategy. Recall that the estimated betas for DOL are close to one and therefore the finding does not come as a surprise. The DOL factor only explains the average level of excess returns for currency portfolios. The cross-sectional $R^{2}$ is very high at $98 \%$ for all and $86 \%$ for developed country samples. The mean absolute pricing error is reasonably low at $0.02 \%$ and $0.06 \%$ for all and developed country samples, respectively. The $\chi^{2}$-statistics based on the GMM-HAC and Shanken (1992) suggest that the null hypothesis of no joint pricing errors cannot be rejected: all of the $p$-values exceed $10 \%$. The results of the estimations are qualitatively and quantitatively similar when portfolio returns are adjusted for transaction costs (see Table IA3 in the Internet Appendix).

Overall, our results suggest that the pricing effect of global FX volatility on the crosssection of carry trade returns recorded in existing studies is due to the pricing effect of the longrun component of FX volatility. Although, this finding confirms some preliminary evidence reported in earlier studies in the context of FX markets, it is different from the results recorded in Adrian and Rosenberg (2008), who show that both components of stock market volatility exert a pricing effect on the cross-section of US equity returns. The difference between these 
two results can be rationalized on the ground of different institutional settings characterizing FX and US equity markets. In fact, Adrian and Rosenberg (2008, p. 3012) argue that the shortrun component of market volatility is correlated with the tightness of financial constraints and price impact of large trades of portfolio managers. It is well-known that FX markets are less regulated than equity markets. Hence, it is easier for currency managers to leverage their positions (King, Osler, and Rime (2011)). As a consequence, in FX markets financial constraints may bind less than in equity markets. In addition, FX markets exhibit smaller price impact of trades as the amounts traded are an order of magnitude larger than equity markets (Mancini, Ranaldo, and Wrampelmeyer (2013)). ${ }^{18}$ These differences suggest that, if short-run volatility pricing effects are really due to binding financial constraints and to price impact of large trades, such effects may exert less power on the cross-section of carry trade returns.

\section{Robustness}

\subsection{Alternative Volatility Decompositions}

The asset pricing tests reported in Section 4 are based on the estimates of the CGARCH model discussed in Section 3. In this section, we assess the robustness of our baseline results to alternative volatility decomposition methods which do not necessarily rely on GARCH model estimations. More specifically, we decompose global FX volatility into transitory/shortrun and persistent/long-run components using the following methodologies: (1) two-factor stochastic volatility model of the price range proposed by Alizadeh, Brandt, and Diebold (2002); ${ }^{19}$ (2) Hodrick and Prescott (1997) filter; and (3) Beveridge and Nelson (1981) decomposition. We have selected these three methodologies as: (1) they have been previously successfully applied in the context of FX markets (Alizadeh, Brandt, and Diebold (2002)); (2) because the estimates of the long-run volatility component are very similar to the ones implied by a CEGARCH model, as suggested by Adrian and Rosenberg (2008 p. 3003-3004); and (3) or for their easier computational implementation in comparison with fully-fledged parametric volatility models. $^{20}$

The results of the asset pricing tests using alternative volatility decompositions are reported in Tables IA4-IA6 of the Internet Appendix. In all cases and across all model

\footnotetext{
${ }^{18}$ This evidence is also corroborated by the results reported in Wrampelmeyer (2012) showing that volatility responses to illiquidity shocks are nearly four time larger in the equity market than the FX market.

${ }^{19}$ See the Internet Appendix for full details of the model.

${ }^{20}$ Permanent-transitory decompositions, generally carried out by variants of the Beveridge and Nelson (1981) decompositions, are also routinely employed in empirical studies in international finance (see, among others, Corsetti and Konstantinou (2012) and the references therein).
} 
specifications, the baseline results discussed in Section 4.2 are confirmed and the parameter estimates obtained using alternative volatility decompositions are qualitatively and quantitatively similar to the ones reported in Table 5.

\subsection{Country-Level Asset Pricing Results}

Early studies routinely assume that carrying out asset pricing tests using portfolios reduces idiosyncratic risk and provides more precise estimates of factor loadings and risk prices (Black, Jensen, and Scholes (1972) and Fama and MacBeth (1973)). However, Lo and MacKinlay (1990) show that sorting assets into portfolios could potentially lead to datasnooping biases and Ang, Liu, and Schwarz (2010) argue that the aggregation procedure of assets may reduce information by shrinking the dispersion of beta estimates for portfolios and therefore leading to larger standard errors for the cross-sectional coefficient estimates. In order to take into account these issues, we perform country-level asset pricing analysis by running two-pass regressions. The test assets are transaction cost unadjusted excess returns on individual currencies. Table 6 presents the estimated factor risk prices from the second-pass cross-sectional regressions for the samples of all and developed countries. We compute the 95\% confidence regions for the point estimates using a bootstrap procedure with 10,000 repetitions. Similar to the portfolio-level analysis, the second-pass regressions do not include a constant. We find that the country-level results from the cross-sectional regressions are also consistent with those for the portfolio-level. The factor risk price estimate for the long-run component of global FX volatility, $\hat{\lambda}_{L R V I}$, is negative across samples and regression specifications. The $95 \%$ confidence region for the risk price estimate does not encompass zero. But the point estimate shrinks in absolute value (toward zero) for both samples relative to those obtained for currency portfolios. Conversely, the $95 \%$ confidence region comfortably encompasses zero for the short-run volatility component. The risk price estimate of the DOL factor is significant for the sample of all countries. This is not unusual since beta estimates for the factor have now much more heterogeneity. But the risk price estimate for the factor remains insignificant for the developed country sample. The $R^{2}$ measure of cross-sectional fit is much lower than those found for currency portfolios. This is expected as well since excess returns for individual currencies are far noisier than forward discount-sorted portfolio returns. However, the $R^{2}$ value drops severely and becomes negative for the all country sample when the two-pass regression excludes innovations of the long-run component. Summing up, these results clearly indicate that innovations in the long-run component of global FX volatility explain the cross-section of individual currency excess returns. 


\subsection{Results for Subperiods}

We also conduct time-series and cross-sectional regressions by splitting the full sample period into two distinct subperiods: May 1987-March 2000 and April 2000-February 2013. The latter subperiod covers both the dot-com bubble and the financial crisis of 2007-2009. The results of this exercise, reported in Table IA7 of the internet appendix, confirm qualitatively and quantitatively the ones reported in Table 5 of the main text. The estimated factor risk price for the short-run component of global FX volatility is insignificantly different from zero regardless of subperiods. On the other hand, the risk price estimates for the long-run volatility component are -0.076 and -0.103 for the first and second halves of the full sample period, respectively. These point estimates are also within the confidence interval around the point estimate of the full sample period. But the results are stronger for the second half of the full sample period in terms of statistical significance and the $R^{2}$ value. Most of the developing currencies become available during this subperiod, which therefore contains more data points.

\subsection{Portfolios Based on Volatility Component Betas}

As a further robustness check, we build portfolios of currencies sorted on their exposure to innovations in the long-run component of global FX volatility. The notion is that if the longrun component is a priced risk factor, then these portfolios are likely to generate a significant spread in average excess returns. The currency sorting procedure mainly follows Lustig, Roussanov, and Verdelhan (2011). First, in each month $t$, we obtain the long-run volatility component beta for currency $k$ by regressing corresponding transaction cost unadjusted excess return on a constant and innovations of the long-run component under a 36-month rolling window ending in month $t-1$. For this purpose, we reestimate the CGARCH model each month to avoid a look-ahead bias. Next, we allocate currencies available in the underlying sample to five portfolios according to their beta estimates for month $t$ and repeat the whole process every month. Portfolio 1 contains currencies in the lowest long-run volatility component beta quintile, while portfolio 5 contains currencies in the highest volatility component beta quintile. Furthermore, we consider an analogous set of quintile portfolios but with currencies sorted on the short-run volatility component betas. ${ }^{21}$

\footnotetext{
${ }^{21}$ We do not find any meaningful pattern in annualized mean excess returns or/and forward discounts for portfolios and therefore do not report them in the paper. Besides, we abstain from double sorting currencies since it yields missing observations in many months, especially for portfolios based on the sample comprising developed countries.
} 
Table 7 reports the summary statistics for the long-run component innovations exposure sorted portfolios based on the samples of all and developed countries. Annualized excess returns and forward discounts monotonically decrease when moving from portfolio 1 to portfolio 5 based on all country sample. The pattern is decreasing (nearly monotone) for the sample of developed countries. The excess return for the HML portfolio (in this case, the excess return difference between portfolio 1 and portfolio 5) is about $3 \%$ for both samples. Portfolios with currencies in relatively low long-run volatility component beta quintile correspond to relatively high average excess returns, while those with currencies in high volatility beta quintile correspond to low average excess returns. We find variation in skewness for excess return distribution compared to those for forward discount-sorted portfolios reported in Tables 1 and IA1.

The empirical results presented convey two important messages. First, sorting currencies on exposure to innovations in the long-run volatility component is similar to sorting based on forward discounts. The currency-based risk factor produces spreads in average excess returns across portfolios, a characteristic similar to that of forward discount sorts. Second, the long-run volatility component beta-sorted portfolios are largely related, but not identical, to the conventional carry trade portfolios. These suggest that the long-run volatility is a key state variable driving risk premia in the cross-section of trading currencies confirming the results of the asset pricing tests reported in Section 4.2.

\section{FX Volatility Risk and Macroeconomic Fundamentals}

This section extends the evidence provided in the previous sections by investigating the empirical relationship between the long-run component of global FX volatility and observable macroeconomic fundamentals. Since the influential paper by Meese and Rogoff (1983), studies in international finance have focused their attention towards explaining the missing link between exchange rate variations and macroeconomic fundamentals. Although a large literature has been able to relate FX movements to macroeconomic news (see, among others, Andersen and Bollerslev (1998), Andersen, Bollerslev, Diebold, and Vega (2003), Engel, Mark, and West (2008), and Evans and Lyons (2008)), very little success has been recorded to date to link the dynamics of macroeconomic variables to carry trade payoffs (Burnside, Eichenbaum, Kleshchelski, and Rebelo (2011), Burnside (2012), and the references therein). It is therefore logical to ask whether an existing relationship between the long-run component of global FX volatility and macroeconomic variables can be empirically established. Along this 
line of reasoning, recent studies have shown that the long-run component of stock returns volatility is correlated with shocks to macroeconomic fundamentals such as real output, money balances, inflation, and interest rates (Adrian and Rosenberg (2008), Engle and Rangel (2008), and Engle, Ghysels, and Sohn (2013)). Nonetheless, for the FX market, this evidence is not widely present and certainly not conclusive. In fact, a host of new studies have recently tried to provide a more exhaustive answer to this question with mixed results (Verdelhan (2013), Della Corte, Riddiough, and Sarno (2014), and Lustig, Verdelhan, and Roussanov (2014)).

We aim at shedding some new light on this important issue in the context of FX market by running a three-variable vector autoregression (VAR) system including the long-run component of global FX volatility and two US macroeconomic fundamentals. In light of the findings of existing studies, we select US industrial production and US money balances as suitable macroeconomic fundamentals. ${ }^{22}$ The impulse response functions (IRFs) from the third-order VAR model are reported in Figure $2 .{ }^{23}$ The response of the long-run component to a unit positive shock in the industrial production growth is reported in the upper panel and show a negative and significant reaction for a prolonged period (from month 2 to month 13). Intuitively, an increase in US output improves expectations of market participants across countries, which in turn lowers FX volatility in the long-run.

The IRF reported in the lower panel of Figure 2 shows that the long-run component is also dynamically related to money balances growth. More precisely, an expansionary US monetary policy induced by an increase in money supply increases FX volatility for a period of time.

The analysis of the IRFs sheds some light on our earlier findings that currencies with a low interest rate covary positively with innovations in the long-run component, while currencies with a high interest rate covary negatively. Intuitively, when the long-run component of global FX volatility driven by shocks to US macroeconomic fundamentals increases, low interest rate currencies provide a hedge but expected to earn lower excess returns on average since the risk price is negative. The high interest rates currencies in this case suffer and therefore investors require a larger compensation reflected by higher excess returns. In this

\footnotetext{
${ }^{22}$ The seasonally adjusted industrial production data are from the IMF International Financial Statistics. We consider monthly growth rate. As a proxy for money balances, we use data on seasonally adjusted M1 stock from the Federal Reserve Bank of St. Louis. Similar to industrial production, we consider monthly growth rate of the M1 time-series.

${ }^{23}$ We report the estimated IRFs for a unit positive shock with the $95 \%$ confidence intervals. The order of the VAR is chosen based on the Schwartz Bayesian Information Criterion.
} 
regard, our empirical findings suggest that the dynamics of macroeconomic fundamentals indirectly influence carry trade returns through the FX volatility risk channel.

\section{Conclusion}

This paper investigates the cross-sectional pricing of volatility risk for carry trade returns by decomposing global FX volatility into short- and long-run components. Inspired by the recent literature investigating the risk determinants of FX carry trade returns, and in the light of the successful results recorded by Menkhoff, Sarno, Schmeling, and Schrimpf (2012), we adopt a cross-sectional asset pricing framework to explore whether the pricing power the global FX volatility factor originates from the persistent component of the FX volatility or from the transitory components or a combination of both. The investigation of this important issue follows the mounting empirical evidence documenting that the volatility of asset returns is better characterized by two factors, rather than a single one, which affects separate dimensions of the return's frequencies and, most importantly, have different economic rationales.

The results of our empirical investigation show that the long-run component of global FX volatility is an empirically important state variable determining the risk premia in the crosssection of carry trade returns. Particularly, we find a statistically significant and negative price for this currency-based risk factor. Currencies with low interest rates comove positively with the long-run volatility component innovations and therefore offer insurance during times of unexpected volatility surges. But they earn lower excess returns in good times. In contrast, high interest rate currencies comove negatively and demand a higher compensation as they suffer during times of heightened market turmoil. Nevertheless, we do not find any significant evidence of the cross-sectional pricing ability of the short-run component of global FX volatility.

The findings are robust to a battery of robustness checks including different methodologies and parametrizations of the models used to obtain the volatility components, different empirical specifications, including country-level asset pricing, different sample periods, and portfolios sorted on beta-exposure to innovations in the long-run component. We also find that the dynamics of the long-run component of global FX volatility are related to US macroeconomic fundamentals, particularly industrial production and money balances, suggesting an interesting channel through which macroeconomic fundamentals affect the cross-section of carry trade returns. 


\section{References}

Adrian, Tobias, and Joshua Rosenberg, 2008, Stock Returns and Volatility: Pricing the Shortrun and Long-run Components of Market Risk, Journal of Finance 63, 2997-3030.

Alizadeh, Sassan, Michael Brandt, and Francis X. Diebold, 2002, Range-Based Estimation of Stochastic Volatility Models, Journal of Finance 57, 1047-1091.

Andersen, Torben G., and Tim Bollerslev, 1997, Heterogeneous Information Arrivals and Return Volatility Dynamics: Uncovering the Long-run in High-frequency Returns, Journal of Finance 52, 975-1005.

Andersen, Torben G., and Tim Bollerslev, 1998, Deutsche Mark-Dollar Volatility: Intraday Activity Patterns, Macroeconomic Announcements, and Longer Run Dependencies, Journal of Finance 53, 219-265.

Andersen, Torben G., Tim Bollerslev, Francis X. Diebold, and Clara Vega, 2003, Micro Effects of Macro Announcements: Real-Time Price Discovery in Foreign Exchange, American Economic Review 93, 38-62.

Andersen, Torben G., Tim Bollerslev, Francis X. Diebold, and Paul Labys, 2003, Modeling and Forecasting Realized Volatility, Econometrica 71, 579-625.

Ang, Andrew, Jun Liu, and Krista Schwarz, 2010, Using Stocks or Portfolios in Tests of Factor Models, Working Paper, Columbia University.

Beveridge, Stephen, and Charles R. Nelson, 1981, A New Approach to Decomposition of Economic Time Series into Permanent and Transitory Components with Particular Attention to Measurement of the 'Business Cycle', Journal of Monetary Economics 7, $151-174$.

Black, Fisher, Michael Jensen, and Myron Scholes, 1972, The Capital Asset Pricing Model: Some Empirical Tests, in Michael Jensen, eds.: Studies in the Theory of Capital Markets, New York: Praeger.

Bollerslev, Tim, and Hao Zhou, 2006, Volatility Puzzles: A Simple Framework for Gauging Return-Volatility Regressions, Journal of Econometrics 131, 123-150.

Bollerslev, Tim, and Jeffrey M. Wooldridge, 1992, Quasi-Maximum Likelihood Estimation and Inference in Dynamic Models with Time-Varying Covariances, Econometric Reviews 11, 143-172. 
Brunnermeier, Markus, Stefan Nagel, and Lasse H. Pedersen, 2009, Carry Trades and Currency Crashes, NBER Macroeconomics Annual 2008 23, 313-347.

Burnside, Craig, 2012, Carry Trades and Risk, in Jessica James, Ian W. Marsh, and Lucio Sarno, eds.: Handbook of Exchange Rates, Hoboken: John Willey \& Sons.

Burnside, Craig, Martin Eichenbaum, and Sergio Rebelo, 2007, The Returns to Currency Speculation in Emerging Markets, American Economic Review (Papers and Proceedings) 97, 333-338.

Burnside, Craig, Martin Eichenbaum, and Sergio Rebelo, 2011, Carry Trade and Momentum in Currency Markets, Annual Review of Financial Economics 3, 511-536.

Burnside, Craig, Martin Eichenbaum, Isaac Kleshchelski, and Sergio Rebelo, 2011, Do Peso Problems Explain the Returns to the Carry Trade?, Review of Financial Studies 24, 853-891.

Byrne, Joseph P., and Eric P. Davis, 2005, The Impact of Short- and Long-run Exchange Rate Uncertainty on Investment: A Panel Study of Industrial Countries, Oxford Bulletin of Economics and Statistics 67, 307-329.

Caporin, Massimiliano, and Michael McAleer, 2010, Model Selection and Testing of Conditional and Stochastic Volatility Models, Working Paper, University of Padova.

Chernov, Mikhail, Ronald A. Gallant, Eric Ghysels, and George Tauchen, 2003, Alternative Models for Stock Price Dynamics, Journal of Econometrics 116, 225-257.

Christoffersen, Peter, Kris Jacobs, Chayawat Ornthanalai, and Yintian Wang, 2008, Option Valuation with Long-run and Short-run Volatility Components, Journal of Financial Economics 90, 272-297.

Cochrane, John H., 2005, Asset Pricing, Revised Edition, Princeton: Princeton University Press.

Corsetti, Giancarlo, and Panagiotis Th. Konstantinou, 2012, What Drives US Foreign Borrowing? Evidence on the External Adjustment to Transitory and Permanent Shocks, American Economic Review 102, 1062-1092.

Della Corte, Pasquale, Steven J. Riddiough, and Lucio Sarno, 2014, Currency Premium and Global Imbalances, Working Paper, Imperial College London.

Engel, Charles, 1996, The Forward Discount Anomaly and the Risk Premium: A Survey of Recent Evidence, Journal of Empirical Finance 3, 123-192. 
Engel, Charles, Nelson C. Mark, and Kenneth D. West, 2008, Exchange Rate Models Are Not as Bad as You Think, NBER Macroeconomics Annual 2007 22, 381-441.

Engle, Robert F., and Gary G. J. Lee, 1999, A Long-run and Short-run Component Model of Stock Return Volatility, in Robert F. Engle, and Halbert L. White, eds.: Cointegration, Causality, and Forecasting: A Festschrift in Honor of Clive W. J. Granger, New York: Oxford University Press.

Engle, Robert F., and Jose G. Rangel, 2008, The Spline-GARCH Model for Low-Frequency Volatility and Its Global Macroeconomic Causes, Review of Financial Studies 21, $1187-1222$.

Engle, Robert F., Eric Ghysels, and Bumjean Sohn, 2013, Stock Market Volatility and Macroeconomic Fundamentals, Review of Economics and Statistics 95, 776-797.

Evans, Martin D. D., and Richard K. Lyons, 2008, How is Macro News Transmitted to Exchange Rates?, Journal of Financial Economics 88, 26-50.

Fama, Eugene F., 1984, Forward and Spot Exchange Rates, Journal of Monetary Economics $14,319-338$.

Fama, Eugene F., and James D. MacBeth, 1973, Risk, Return, and Equilibrium: Empirical Tests, Journal of Political Economy 81, 607-636.

Fama, Eugene F., and Kenneth R. French, 1993, Common Risk Factors in the Returns on Stocks and Bonds, Journal of Financial Economics 33, 3-56.

Hansen, Lars P., and Robert J. Hodrick, 1980, Forward Exchange Rates as Optimal Predictors of Future Spot Rates: An Econometric Analysis, Journal of Political Economy 88, 829853.

Hodrick, Robert J., and Edward C. Prescott, 1997, Postwar U.S. Business Cycles: An Empirical Investigation, Journal of Money, Credit, and Banking 29, 1-16.

Inoue, Atsushi, and Lutz Kilian, 2004, In-Sample or Out-of-Sample Tests of Predictability: Which One Should We Use? Econometric Reviews 23, 371-402.

Inoue, Atsushi, and Lutz Kilian, 2006. On the Selection of Forecasting Models. Journal of Econometrics 130, 273-306.

Jagannathan, Ravi, and Zhenyu Wang, 1998, An Asymptotic Theory for Estimating BetaPricing Models Using Cross-Sectional Regression, Journal of Finance 53, 1285-1309. 
King, Michael R., Carol Osler, and Dagfinn Rime, 2011, Foreign Exchange Market Structure, Players and Evolution, Norges Bank Working Paper.

Kobayashi, Masahito, and Xiuhong Shi, 2005, Testing for EGARCH Against Stochastic Volatility Models, Journal of Time Series Analysis 26, 135-150.

Lee, Jung-Hee, and B. Wade Brorsen, 1997, A Non-nested Test of GARCH vs. EGARCH Models, Applied Economic Letters 4, 765-768.

Liesenfeld, Roman, 2001, A Generalized Bivariate Mixture for Stock Price Volatility and Trading Volume, Journal of Econometrics 116, 181-224.

Ljung, Greta M., and George E. P. Box, 1978, On a Measure of Lack of Fit in Time Series Models, Biometrika 65, 297-303.

Lo, Andrew W., and Andrew C. MacKinlay, 1990, Data-Snooping Biases in Tests of Financial Asset Pricing Models, Review of Financial Studies 3, 431-467.

Lustig, Hanno, and Adrien Verdelhan, 2007, The Cross-Section of Foreign Currency Risk Premia and Consumption Growth Risk, American Economic Review 97, 89-117.

Lustig, Hanno, Nikolai Roussanov, and Adrien Verdelhan, 2011, Common Risk Factors in Currency Markets, Review of Financial Studies 24, 3731-3777.

Lustig, Hanno, Nikolai Roussanov, and Adrien Verdelhan, 2014, Countercyclical Currency Risk Premia, Journal of Financial Economics 111, 527-553.

Lyons, Richard K., 2001, The Microstructure Approach to Exchange Rates, MIT Press.

MacKinlay, Andrew C., and Jong W. Park, 2004, The Relationship between Expected Risk Premium and Conditional Permanent and Transitory Volatility, Working Paper, University of Pennsylvania.

Maheu, John, 2005, Can GARCH Models Capture Long-Range Dependence?, Studies in Nonlinear Dynamics \& Econometrics 9, 1-41.

Mancini, Loriano, Angelo Ranaldo, and Jan Wrampelmeyer, 2013, Liquidity in the Foreign Exchange Market: Measurement, Commonality, and Risk Premiums, Journal of Finance 68, 1805-1841.

Meese, Richard A., and Kenneth Rogoff, 1983, Empirical Exchange Rate Models of the Seventies: Do They Fit Out of Sample?, Journal of International Economics 14, 3-24.

Menkhoff, Lucas, Lucio Sarno, Maik Schmeling, and Andreas Schrimpf, 2012, Carry Trades and Global Foreign Exchange Volatility, Journal of Finance 67, 681-718. 
Merton, Robert C., 1980, On Estimating the Expected Return on the Market: An Exploratory Investigation, Journal of Financial Economics 8, 323-361.

Mincer, Jacob, and Victor Zarnowitz, 1969, The Evaluation of Economic Forecasts, in Jacob Mincer, ed.: Economic Forecasts and Expectations: Analysis of Forecasting Behavior and Performance, 1-46 (National Bureau of Economic Research: New York).

Müller, Ulrich A., Michel M. Dacorogna, Rakhal D. Davé, Richard B. Olsen, Olivier V. Pictet, and Jacob E. von Weizsäcker, 1997, Volatilities of Different Time Resolutions Analyzing the Dynamics of Market Components, Journal of Empirical Finance 4, 213 239.

Nelson, Daniel B., 1992, Filtering and Forecasting with Misspecified ARCH Models I: Getting the Right Variance with the Wrong Model, Journal of Econometrics 52, 61-90.

Newey, Whitney K., and Kenneth D. West, 1987, A Simple, Positive Semi-definite, Heteroskedasticity and Autocorrelation Consistent Covariance Matrix, Econometrica $55,703-708$.

Patton, Andrew J., 2011, Volatility Forecast Comparison Using Imperfect Volatility Proxies, Journal of Econometrics 160, 246-256.

Patton, Andrew J., and Allan Timmermann, 2010, Monotonicity in Asset Returns: New Tests with Applications to the Term Structure, the CAPM, and Portfolio Sorts, Journal of Financial Economics 98, 605-625.

Sarno, Lucio, Giorgio Valente, and Hyginus Leon, 2006, Nonlinearity in Deviations from Uncovered Interest Parity: An Explanation of the Forward Bias Puzzle, Review of Finance 10, 443-482.

Shanken, Jay, 1992, On the Estimation of Beta-Pricing Models, Review of Financial Studies $5,1-33$.

Verdelhan, Adrien, 2013, The Share of Systematic Variation in Bilateral Exchange Rates, Working Paper, MIT Sloan School of Management.

Wrampelmeyer, Jan, 2012, The Joint Dynamics of Hedge Fund Returns, Illiquidity, and Volatility, Journal of Alternative Investments 15, 43-67. 


\section{Table 1}

\section{Descriptive Statistics of Currency Portfolios: All Countries}

The table presents annualized mean, median, standard deviation, and Sharpe ratio for excess returns of each currency portfolio. The portfolios are constructed using all country sample currencies sorted into five groups at the end of each month $t$ based on their one-month forward discounts at the end of month $t$. Portfolio 1 includes $20 \%$ of currencies with the lowest forward discounts, while portfolio 5 includes $20 \%$ of currencies with the highest forward discounts. Avg. denotes the average excess return of the five currency portfolios, while HML denotes the long-short portfolio (i.e., long in portfolio 5 and short in portfolio 1). The table also reports skewness, kurtosis, and first-order autocorrelation coefficient $(\mathrm{AC}(1)$ ) with associated $p$-value for each portfolio. Numbers in brackets are $t$-statistics based on the Newey and West (1987) estimator, while numbers in parentheses are bootstrap $p$ values for tests of mean excess return (increasing) monotonicity when moving from portfolio 1 to portfolio 5 . The monotonic relationship (MR) test is based on Patton and Timmermann (2010). The Sharpe ratios are estimated as ratios of annualized means to annualized standard deviations. Panels A and B report excess returns without and with transaction cost adjustments (with bid-ask spreads), respectively. In panel B, excess returns for portfolio 1 are adjusted for transaction costs that incur in a short position, while those for portfolios 2 to 5 are adjusted for transaction costs that incur in long positions. All excess returns are monthly (\%) reported in USD. The sample period is from May 1987 to February 2013.

\begin{tabular}{|c|c|c|c|c|c|c|c|c|}
\hline \multicolumn{9}{|c|}{ Panel A: Excess Returns (without bid-ask) } \\
\hline Portfolio & 1 & 2 & 3 & 4 & 5 & Avg. & HML & MR \\
\hline Mean & -2.10 & 0.06 & 2.63 & 3.08 & 5.89 & 1.91 & 7.99 & $(0.00)$ \\
\hline & {$[-1.46]$} & {$[0.04]$} & [1.49] & {$[1.72]$} & {$[2.71]$} & {$[1.20]$} & {$[4.58]$} & \\
\hline Median & -1.81 & 2.45 & 2.58 & 5.29 & 9.26 & 3.35 & 11.82 & \\
\hline Std. Dev. & 6.97 & 7.73 & 8.27 & 8.32 & 9.06 & 7.32 & 7.30 & \\
\hline Skewness & -0.15 & -0.76 & -0.58 & -0.82 & -1.05 & -0.73 & -0.93 & \\
\hline Kurtosis & 3.68 & 4.89 & 4.98 & 5.19 & 6.13 & 4.76 & 4.95 & \\
\hline Sharpe Ratio & -0.30 & 0.01 & 0.32 & 0.37 & 0.65 & 0.26 & 1.09 & \\
\hline $\mathrm{AC}(1)$ & 0.08 & 0.06 & 0.11 & 0.14 & 0.22 & 0.14 & 0.20 & \\
\hline$p$-value & 0.14 & 0.27 & 0.06 & 0.02 & 0.00 & 0.02 & 0.00 & \\
\hline \multicolumn{9}{|c|}{ Panel B: Excess Returns (with bid-ask) } \\
\hline Portfolio & 1 & 2 & 3 & 4 & 5 & Avg. & HML & MR \\
\hline Mean & -1.32 & -0.79 & 1.69 & 1.96 & 3.78 & 1.07 & 5.09 & $(0.01)$ \\
\hline & {$[-0.93]$} & {$[-0.50]$} & {$[0.96]$} & [1.09] & [1.97] & {$[0.67]$} & [2.95] & \\
\hline Median & -1.05 & 1.66 & 1.33 & 4.36 & 7.12 & 2.64 & 8.93 & \\
\hline Std. Dev. & 6.91 & 7.73 & 8.27 & 8.33 & 9.02 & 7.31 & 7.24 & \\
\hline Skewness & -0.20 & -0.76 & -0.58 & -0.83 & -1.06 & -0.74 & -0.93 & \\
\hline Kurtosis & 3.58 & 4.89 & 4.99 & 5.21 & 6.13 & 4.76 & 5.00 & \\
\hline Sharpe Ratio & -0.19 & -0.10 & 0.20 & 0.24 & 0.42 & 0.15 & 0.70 & \\
\hline $\mathrm{AC}(1)$ & 0.08 & 0.06 & 0.11 & 0.15 & 0.21 & 0.14 & 0.20 & \\
\hline$p$-value & 0.16 & 0.26 & 0.06 & 0.01 & 0.00 & 0.02 & 0.00 & \\
\hline
\end{tabular}




\section{Table 2 \\ Time-Series Estimation of the Volatility Components}

The table presents the descriptive statistics of the global FX return and the quasi-maximum likelihood estimates of the CGARCH model introduced by Engle and Lee (1999). The global FX return at a daily frequency is computed as $R_{\tau}=\sum_{k \in K_{\tau}}\left[\left(\frac{s_{\tau}^{k}-S_{\tau-1}^{k}}{s_{\tau-1}^{k}}\right) / K_{\tau}\right]$. The equations of the model are: (i) $R_{\tau}=\psi_{1}+\epsilon_{\tau}\left(\right.$ where $\left.\epsilon_{\tau}=\sigma_{\tau} v_{\tau}\right)$ for the conditional mean; (ii) $\sigma_{\tau}^{2}-q_{\tau}=\psi_{2}\left(\epsilon_{\tau-1}^{2}-q_{\tau-1}\right)+\psi_{3}\left(\epsilon_{\tau-1}^{2}-q_{\tau-1}\right) d_{\tau-1}+\psi_{4}\left(\sigma_{\tau-1}^{2}-q_{\tau-1}\right)$ for the shortrun component; and (iii) $q_{\tau}=\psi_{5}+\psi_{6}\left(q_{\tau-1}-\psi_{5}\right)+\psi_{7}\left(\epsilon_{\tau-1}^{2}-\sigma_{\tau-1}^{2}\right)$ for the long-run component. The table also reports the Bollerslev and Wooldridge (1992) robust standard errors with associated $p$-values for the coefficient estimates. Panel D reports diagnostics for the standardized and squared standardized residuals based on the Ljung and Box (1978) $Q$-statistics at 10, 20, and 30 lags, respectively. The sample period is from November 2, 1983 to February 28, 2013.

\begin{tabular}{|c|c|c|c|c|}
\hline \multicolumn{5}{|c|}{ Panel A: Descriptive Statistics of Global FX Return (7,652 Days) } \\
\hline Mean & Median & Std. Dev. & Skewness & Kurtosis \\
\hline 0.001 & 0.000 & 0.419 & -0.086 & 7.096 \\
\hline \multicolumn{5}{|c|}{ Panel B: Short-Run Component } \\
\hline & $\widehat{\psi_{2}}$ & $\widehat{\psi_{3}}$ & $\widehat{\psi_{4}}$ & \\
\hline Coef. & 0.020 & -0.039 & 0.879 & \\
\hline Std. Err. & 0.008 & 0.018 & 0.096 & \\
\hline$p$-value & 0.012 & 0.031 & 0.000 & \\
\hline \multicolumn{5}{|c|}{ Panel C: Long-Run Component } \\
\hline & $\widehat{\psi_{5}}$ & $\widehat{\psi_{6}}$ & $\widehat{\psi_{7}}$ & \\
\hline Coef. & 0.178 & 0.994 & 0.041 & \\
\hline Std. Err. & 0.040 & 0.002 & 0.005 & \\
\hline$p$-value & 0.000 & 0.000 & 0.000 & \\
\hline \multicolumn{4}{|c|}{0.023} & \\
\hline \multicolumn{5}{|c|}{ Panel D: Diagnostics of the Model } \\
\hline & & 10 lags & 20 lags & 30 lags \\
\hline Ljung-B & of $\hat{v}$ & 11.952 & 23.164 & 32.567 \\
\hline$p$-value & & 0.288 & 0.319 & 0.342 \\
\hline Ljung-B & of $\hat{v}^{2}$ & 13.357 & 18.927 & 23.590 \\
\hline$p$-value & & 0.204 & 0.527 & 0.790 \\
\hline Log-like & & & & \\
\hline
\end{tabular}




\section{Table 3}

\section{Time-Series Estimation of the Volatility Components: Adrian and Rosenberg (2008) \\ Model}

The table presents the maximum likelihood estimates of the CEGARCH model introduced by Adrian and Rosenberg (2008). The global FX return at a daily frequency is obtained as $R_{\tau}=\sum_{k \in K_{\tau}}\left[\left(\frac{s_{\tau}^{k}-S_{-1}^{k}}{s_{\tau-1}^{k}}\right) / K_{\tau}\right]$. The equations of the model are: (i) $R_{\tau}=\theta_{1}+\theta_{2} s_{\tau-1+} \theta_{3} l_{\tau-1+} \sqrt{v_{\tau-1}} \varepsilon_{\tau}$ (where $\log \sqrt{v_{\tau}}=s_{\tau}+l_{\tau}$ ) for the conditional mean; (ii) $s_{\tau}=\theta_{4} s_{\tau-1}+\theta_{5} \varepsilon_{\tau}+\theta_{6}\left(\left|\varepsilon_{\tau}\right|-\sqrt{2 / \pi}\right)$ for the short-run component; and (iii) $l_{\tau}=\theta_{7}+\theta_{8} l_{\tau-1}+$ $\theta_{9} \varepsilon_{\tau}+\theta_{10}\left(\left|\varepsilon_{\tau}\right|-\sqrt{2 / \pi}\right)$ for the long-run component. Panel D reports diagnostics for the squared standardized residuals based on the Ljung and Box (1978) $Q$-statistics at 10, 20, and 30 lags, respectively. The sample period is from November 2, 1983 to February 28, 2013.

\begin{tabular}{|c|c|c|c|c|}
\hline \multicolumn{5}{|c|}{ Panel A: Conditional Mean } \\
\hline & $\widehat{\theta_{1}}$ & $\widehat{\theta_{2}}$ & $\widehat{\theta_{3}}$ & \\
\hline Coef. & 0.093 & -0.006 & 0.046 & \\
\hline Std. Err. & 0.019 & 0.001 & 0.009 & \\
\hline$p$-value & 0.000 & 0.000 & 0.000 & \\
\hline \multicolumn{5}{|c|}{ Panel B: Short-Run Component } \\
\hline & $\widehat{\theta_{4}}$ & $\widehat{\theta_{5}}$ & $\widehat{\theta_{6}}$ & \\
\hline Coef. & 0.466 & 0.005 & 0.309 & \\
\hline Std. Err. & 0.020 & 0.001 & 0.015 & \\
\hline$p$-value & 0.000 & 0.000 & 0.000 & \\
\hline \multicolumn{5}{|c|}{ Panel C: Long-Run Component } \\
\hline & $\widehat{\theta_{7}}$ & $\widehat{\theta_{8}}$ & $\widehat{\theta_{9}}$ & $\widehat{\theta_{10}}$ \\
\hline Coef. & -0.049 & 0.992 & 0.008 & 0.063 \\
\hline Std. Err. & 0.011 & 0.004 & 0.007 & 0.010 \\
\hline p-value & 0.000 & 0.000 & 0.253 & 0.000 \\
\hline \multicolumn{4}{|c|}{$p$-value of $H_{0}$ : } & \\
\hline \multicolumn{5}{|c|}{ Panel D: Diagnostics of the Model } \\
\hline & & 10 lags & 20 lags & 30 lags \\
\hline Ljung-Bo & $\mathrm{c}$ of $\hat{\varepsilon}^{2}$ & 109.659 & 118.853 & 127.003 \\
\hline$p$-value & & 0.000 & 0.000 & 0.000 \\
\hline Log-likel & & & & \\
\hline
\end{tabular}




\section{Table 4}

\section{Comparison of Global FX Volatility Forecasts}

The table reports $t$-statistics for the tests of equal predictive accuracy of the forecasts from the CGARCH and CEGARCH models as in Patton (2011). The tests are performed using both daily and monthly average of daily global FX volatility forecasts. The forecast errors are obtained in comparison with global FX daily and monthly average squared returns. The loss functions and the values of the loss function parameter $c$ are as suggested in Patton (2011, p. 252-253). The rejection of the null hypothesis suggests that the baseline CGARCH model forecasts generate significantly different average loss than the CEGARCH model forecasts. The out-of-sample forecasts for May 1, 1987 to February 28, 2013 are obtained using a 914-day rolling window scheme.

\begin{tabular}{lrr} 
Loss Function & Global FX Daily Squared Return & Global FX Monthly Average Squared Return \\
\hline \multirow{2}{*}{$c=1$} & -1.11 & -1.26 \\
$c=0$ (MSE) & -0.81 & -0.94 \\
$c=-1$ & 0.78 & 0.66 \\
$c=-2$ (QLIKE) & 1.61 & 1.57 \\
$c=-5$ & 0.63 & 0.71 \\
\hline
\end{tabular}




\section{Table 5}

\section{Asset Pricing Results: Short-Run and Long-Run Components of Volatility}

The table presents asset pricing results from the Fama and MacBeth (1973) two-pass regressions for the linear factor model based on the dollar risk factor (DOL), short-run volatility component innovations (SRVI), and long-run volatility component innovations (LRVI). The test assets are transaction cost unadjusted (without bid-ask spreads) excess returns of five portfolios constructed using currencies from all and developed country samples, respectively. Panel A shows results for the first-pass time-series regressions where excess returns are regressed on a constant $(\alpha)$, DOL, SRVI, and LRVI. Panel B reports factor prices $(\lambda)$ obtained from the second-pass cross-sectional regressions without a constant. Numbers in brackets are robust standard errors based on the GMM-HAC procedure, while numbers in parentheses are the Shanken (SH, 1992) corrected standard errors. The table also reports $R^{2}$, mean absolute pricing error (MAE), and $\chi^{2}$-statistics with associated $p$-values for tests of pricing errors based on the GMMHAC and SH adjustment methods. All excess returns are monthly (\%) and the sample period is from May 1987 to February 2013.

\begin{tabular}{|c|c|c|c|c|c|c|c|c|c|c|c|}
\hline \multicolumn{12}{|c|}{ Panel A: Factor Betas } \\
\hline \multicolumn{6}{|c|}{ All Countries (without bid-ask) } & \multicolumn{6}{|c|}{ Developed Countries (without bid-ask) } \\
\hline Portfolio & $\hat{\alpha}$ & DOL & SRVI & LRVI & $R^{2}$ & Portfolio & $\hat{\alpha}$ & DOL & SRVI & LRVI & $R^{2}$ \\
\hline \multirow[t]{2}{*}{1} & -0.308 & 0.842 & 1.457 & 3.151 & 0.743 & 1 & -0.233 & 0.859 & -0.003 & 5.592 & 0.623 \\
\hline & [0.059] & {$[0.038]$} & {$[3.723]$} & [1.032] & & & [0.092] & [0.055] & [7.014] & [3.266] & \\
\hline \multirow[t]{2}{*}{2} & -0.151 & 0.983 & 0.464 & 1.344 & 0.849 & 2 & -0.105 & 1.038 & 1.937 & 1.037 & 0.817 \\
\hline & [0.051] & {$[0.035]$} & {$[2.907]$} & [0.918] & & & [0.068] & [0.038] & [4.391] & [1.288] & \\
\hline \multirow[t]{2}{*}{3} & 0.051 & 1.058 & -5.129 & -0.340 & 0.906 & 3 & 0.004 & 1.006 & -4.967 & -1.210 & 0.885 \\
\hline & {$[0.042]$} & {$[0.025]$} & {$[2.702]$} & {$[0.744]$} & & & {$[0.051]$} & {$[0.024]$} & {$[3.001]$} & [0.951] & \\
\hline \multirow[t]{2}{*}{4} & 0.086 & 1.066 & 4.027 & -0.677 & 0.872 & 4 & 0.105 & 1.011 & 3.733 & -2.901 & 0.818 \\
\hline & {$[0.054]$} & {$[0.036]$} & {$[3.307]$} & [1.020] & & & [0.068] & [0.037] & {$[4.536]$} & [1.874] & \\
\hline \multirow[t]{2}{*}{5} & 0.322 & 1.052 & -0.819 & -3.478 & 0.767 & 5 & 0.229 & 1.087 & -0.700 & -2.518 & 0.739 \\
\hline & {$[0.073]$} & {$[0.044]$} & {$[4.352]$} & [1.372] & & & [0.093] & {$[0.053]$} & [6.485] & [1.312] & \\
\hline \multicolumn{12}{|c|}{ Panel B: Factor Prices } \\
\hline \multicolumn{6}{|c|}{ All Countries (without bid-ask) } & \multicolumn{6}{|c|}{ Developed Countries (without bid-ask) } \\
\hline & DOL & SRVI & LRVI & $R^{2}$ & MAE & & DOL & SRVI & LRVI & $R^{2}$ & MAE \\
\hline \multirow[t]{5}{*}{$\hat{\lambda}$} & 0.160 & -0.001 & -0.097 & 0.984 & 0.015 & $\hat{\lambda}$ & 0.104 & -0.001 & -0.048 & 0.859 & 0.056 \\
\hline & {$[0.120]$} & [0.016] & {$[0.040]$} & & & & [0.139] & [0.014] & [0.026] & & \\
\hline & $(0.120)$ & $(0.012)$ & $(0.034)$ & & & & $(0.139)$ & $(0.012)$ & $(0.021)$ & & \\
\hline & $\chi_{G M M-H A C}^{2}$ & $\chi_{S H}^{2}$ & & & & & $M-H A C$ & $\chi_{S H}^{2}$ & & & \\
\hline & 0.129 & 0.133 & & & & & 1.195 & 1.662 & & & \\
\hline$p$-value & 0.938 & 0.936 & & & & $p$-value & 0.550 & 0.436 & & & \\
\hline
\end{tabular}


Table 6

\section{Country-Level Asset Pricing Results}

The table presents cross-sectional asset pricing results from the Fama and MacBeth (1973) second-pass regressions for the linear factor model based on the dollar risk factor (DOL), short-run volatility component innovations (SRVI), and long-run volatility component innovations (LRVI). The test assets are transaction cost unadjusted excess returns (without bid-ask spreads) of individual currencies. The second-pass cross-sectional regressions are performed without a constant. Panel A shows the estimated factor prices ( $\lambda$ ) for the all country sample, while panel B presents factor prices for the developed country sample. Numbers in parentheses are the $95 \%$ confidence regions based on a bootstrap procedure. See also notes to Table 5.

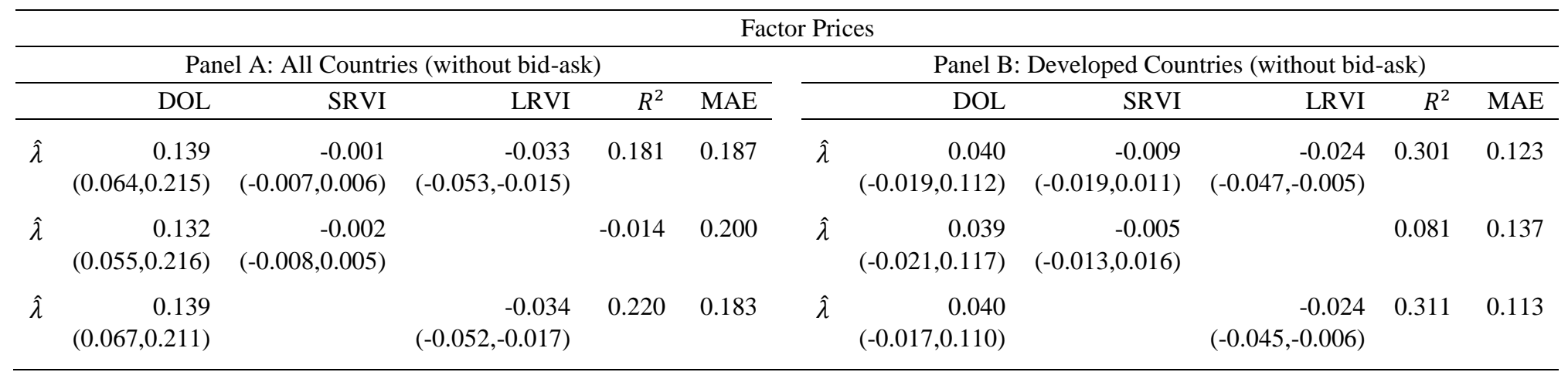




\section{Table 7}

\section{Portfolios Sorted on Long-Run Volatility Component Betas}

The table presents annualized mean, standard deviation, and Sharpe ratio for excess returns of each portfolio. The portfolios are constructed using currencies sorted into five groups based on their exposure to long-run volatility component innovations. The volatility betas for each currency in month $t$ are obtained by regressing respective currency's transaction cost unadjusted (without bid-ask spreads) excess return on a constant and long-run volatility component innovations under a 36-month rolling window that ends in month $t-1$. All portfolios are rebalanced every month. The table also reports skewness, kurtosis, and annualized average $(\%)$ forward discount $[(F-S) / S]$ for each portfolio. Numbers in brackets are $t$-statistics based on the Newey and West (1987) estimator. The Sharpe ratios are estimated as ratios of annualized means to annualized standard deviations. Portfolio 1 includes $20 \%$ of currencies with the lowest long-run volatility component betas, while portfolio 5 includes $20 \%$ of currencies with the highest long-run volatility component betas. Avg. denotes the average excess return of the five beta-sorted portfolios, while HML denotes the long-short portfolio (in this case, long in portfolio 1 and short in portfolio 5). Panel A reports results for portfolios constructed using all country sample currencies, while panel B shows results for developed country sample. Pre-sorting $\left(\right.$ Pre- $\left.\beta_{L R V I}\right)$ and post-sorting (Post- $\left.\beta_{L R V I}\right)$ long-run volatility component betas for all and developed country samples are reported in the last two rows of the corresponding panels. All excess returns are monthly (\%) reported in USD. In each panel, excess returns for the first 36 months are excluded to avoid relying on in-sample estimated volatility component betas for this period. The effective sample period is from May 1990 to February 2013.

\begin{tabular}{|c|c|c|c|c|c|c|c|}
\hline \multicolumn{8}{|c|}{ Panel A: All Countries } \\
\hline Portfolio & 1 & 2 & 3 & 4 & 5 & Avg. & HML \\
\hline Mean & $\begin{array}{r}2.93 \\
{[1.34]}\end{array}$ & $\begin{array}{r}2.16 \\
{[1.13]}\end{array}$ & $\begin{array}{r}1.12 \\
{[0.62]}\end{array}$ & $\begin{array}{r}0.97 \\
{[0.53]}\end{array}$ & $\begin{array}{r}-0.33 \\
{[-0.19]}\end{array}$ & $\begin{array}{r}1.37 \\
{[0.83]}\end{array}$ & $\begin{array}{r}3.26 \\
{[1.76]}\end{array}$ \\
\hline Std. Dev. & 9.54 & 8.68 & 8.31 & 7.53 & 7.32 & 6.96 & 8.82 \\
\hline Skewness & -1.02 & -0.62 & -0.65 & -0.59 & -0.07 & -0.71 & -0.23 \\
\hline Kurtosis & 7.11 & 5.33 & 5.53 & 4.57 & 3.65 & 4.78 & 4.75 \\
\hline Sharpe Ratio & 0.31 & 0.25 & 0.14 & 0.13 & -0.04 & 0.20 & 0.37 \\
\hline$[(F-S) / S]$ & 2.21 & 1.67 & 0.91 & 0.74 & -0.19 & & \\
\hline Pre- $\beta_{L R V I}$ & -19.19 & -8.02 & -3.46 & 0.92 & 8.22 & & \\
\hline Post- $\beta_{L R V I}$ & -0.99 & -0.09 & 1.65 & 0.36 & 2.37 & & \\
\hline \multicolumn{8}{|c|}{ Panel B: Developed Countries } \\
\hline Portfolio & 1 & 2 & 3 & 4 & 5 & Avg. & HML \\
\hline Mean & $\begin{array}{r}2.27 \\
{[0.98]}\end{array}$ & $\begin{array}{r}1.34 \\
{[0.61]}\end{array}$ & $\begin{array}{r}0.76 \\
{[0.35]}\end{array}$ & $\begin{array}{r}0.81 \\
{[0.36]}\end{array}$ & $\begin{array}{r}-0.78 \\
{[-0.42]}\end{array}$ & $\begin{array}{r}0.88 \\
{[0.47]}\end{array}$ & $\begin{array}{r}3.05 \\
{[1.66]}\end{array}$ \\
\hline Std. Dev. & 10.61 & 9.80 & 10.13 & 10.05 & 8.84 & 8.37 & 9.42 \\
\hline Skewness & -0.80 & -0.53 & -0.44 & -0.63 & -0.22 & -0.41 & -0.79 \\
\hline Kurtosis & 6.37 & 5.20 & 4.08 & 5.00 & 4.12 & 4.09 & 6.56 \\
\hline Sharpe Ratio & 0.21 & 0.14 & 0.07 & 0.08 & -0.09 & 0.10 & 0.32 \\
\hline$[(F-S) / S]$ & 1.51 & 1.20 & 0.50 & 0.54 & -0.04 & & \\
\hline Pre- $\beta_{L R V I}$ & -18.03 & -9.57 & -3.48 & 1.10 & 9.48 & & \\
\hline Post- $\beta_{L R V I}$ & -3.12 & -2.44 & 0.23 & -1.20 & 6.89 & & \\
\hline
\end{tabular}


Figure 1

Global FX Volatility Components
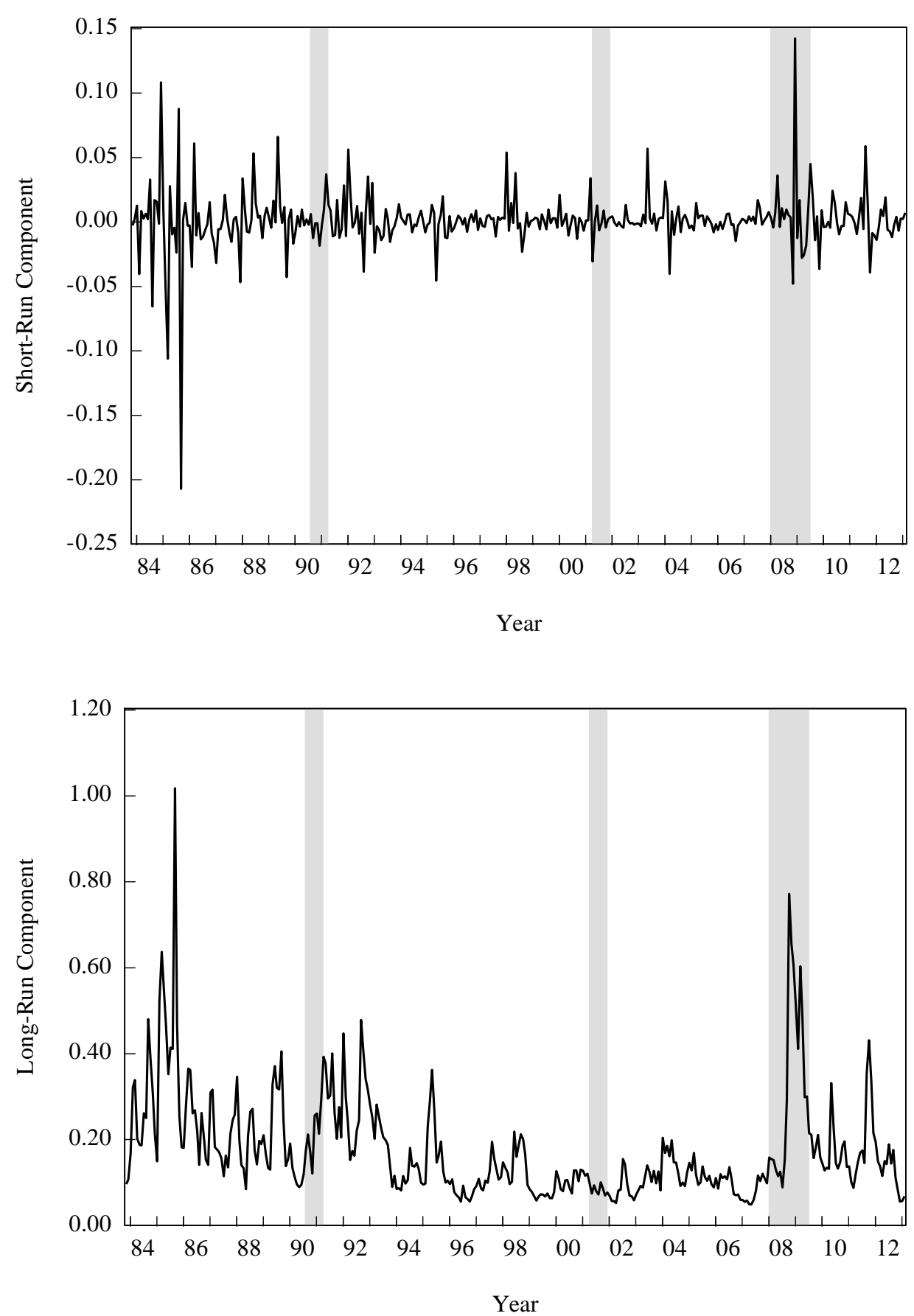

The upper and lower panels of the figure plot the estimated short- and long-run components of global FX volatility at a monthly frequency, respectively. The short- and long-run components are from the CGARCH model reported in Table 2. Shaded areas represent the National Bureau of Economic Research recessions. The sample period is from November 1983 to February 2013. 
Figure 2

Impulse Response Functions for Shocks to Macroeconomic Fundamentals

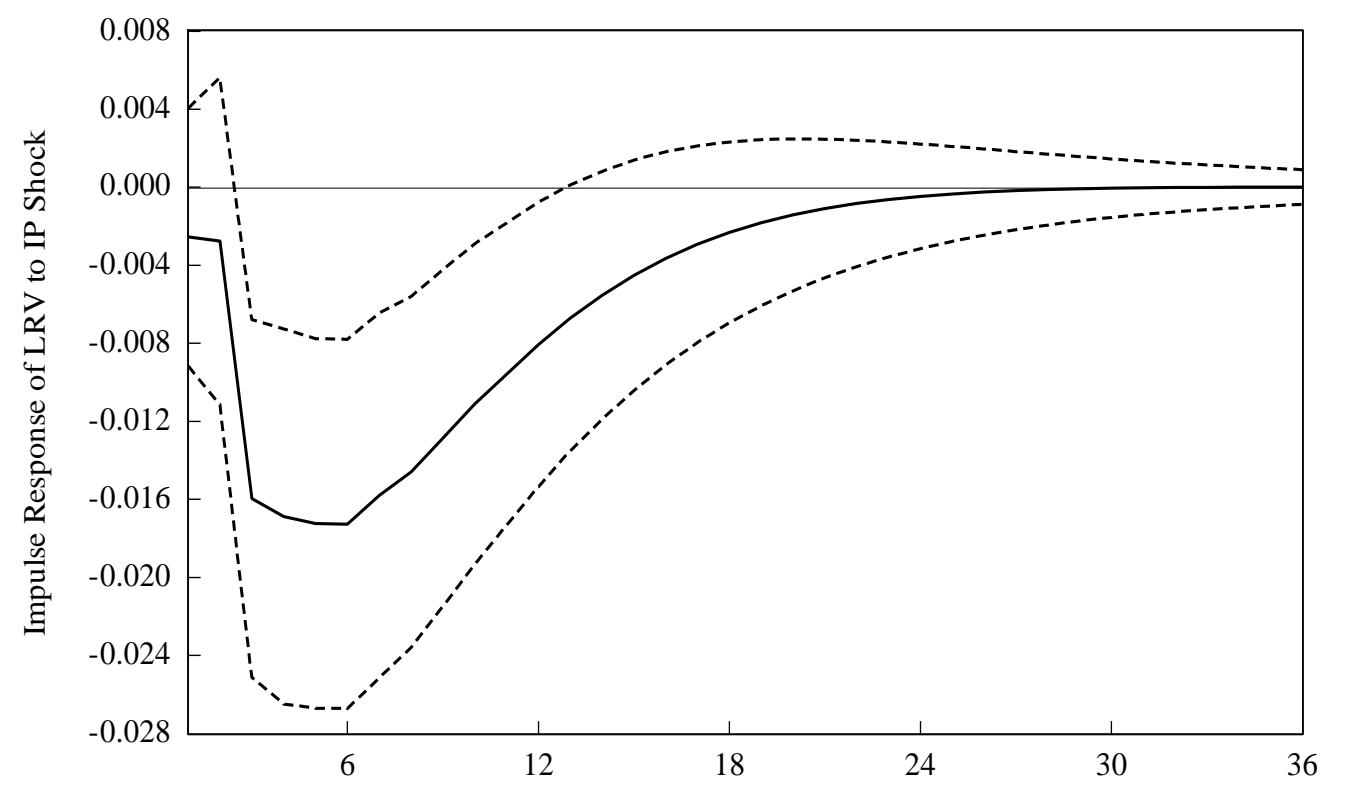

Time Horizon (Month)

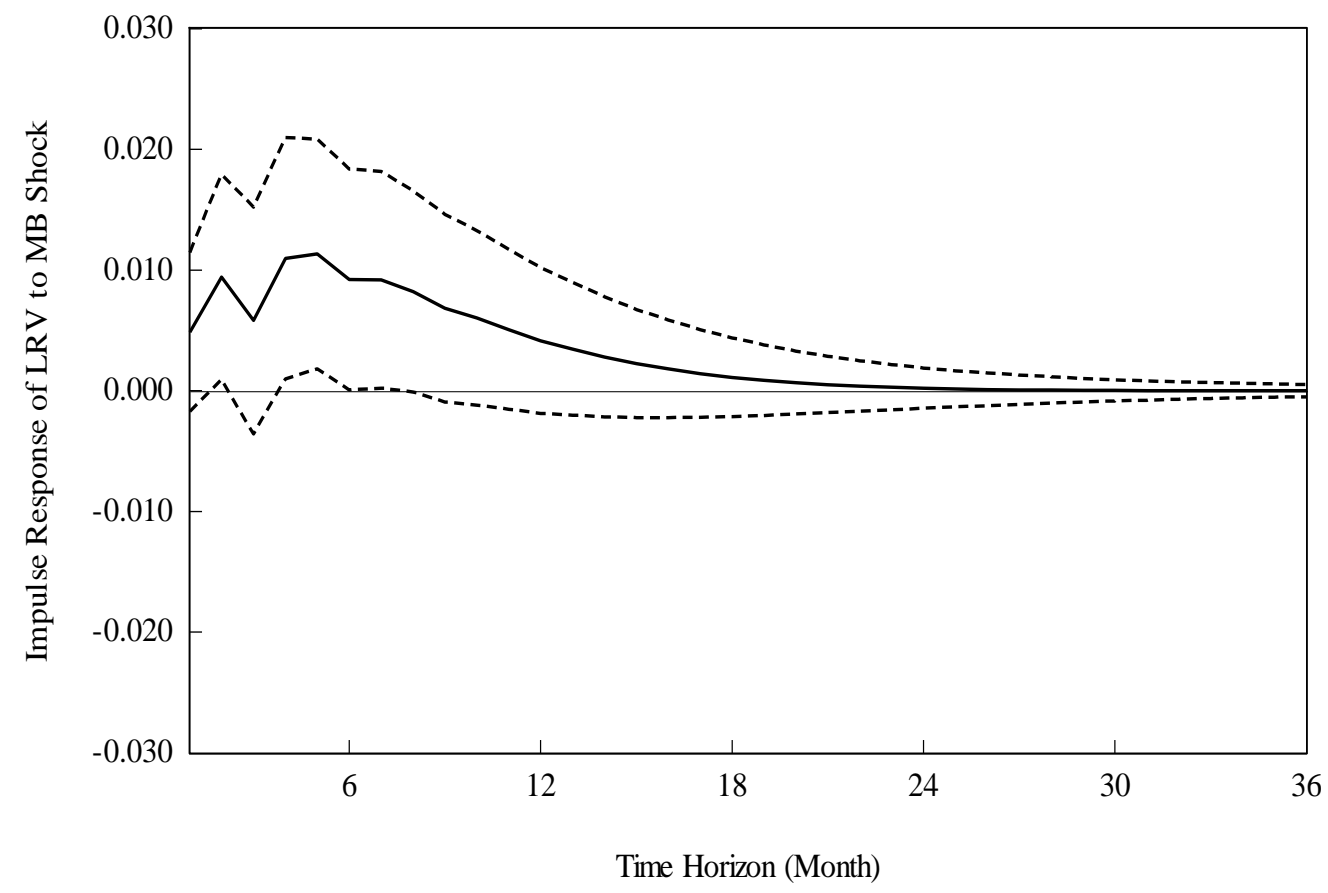

The upper panel of the figure plots impulse response function (IRF) for a unit positive shock to industrial production growth (IP) with the $95 \%$ confidence intervals. The lower panel plots IRF for a unit positive shock to money balances growth (MB) with the $95 \%$ confidence intervals. The (endogenous) variables of VAR(3) are IP, $\mathrm{MB}$, and long-run component (LRV) of global FX volatility. The IRFs are generated through 10,000 Monte Carlo random draws from the orthogonalized residuals with the Choleski ordering of MB, IP, LRV. 